\title{
Instituições de formação profissional - história e perspectivas: o projeto da nova institucionalidade da educação profissional brasileira dos anos 1990
}

Ronaldo Marcos de Lima Araujo*

\section{Resumo}

Problematizamos o projeto da "nova institucionalidade da educação profissional", presente em diferentes programas federais, gerados no Governo Fernando Henrique Cardoso, que pretendia promover uma renovação ampla da educação profissional brasileira. Focamos nos efeitos de diferentes programas de educação profissional sobre o quadro institucional da educação profissional em Belém-PA, no período de 1995 a 2003. Verificamos que estes programas se orientavam por referências identificadas com o pragmatismo e que, por meio de observações e entrevistas, a renovação da educação profissional não se efetivou e que o produto mais evidente do conjunto de ações realizadas foi a reprodução do ideário, segundo o qual a educação profissional deve estar subordinada aos interesses fragmentados e imediatos do mercado. Finalizamos indicando que uma nova educação profissional ainda está por ser construída.

Palavras-chaves: educação profissional. Avaliação de políticas de educação profissional.

\section{Introdução}

Nem toda loucura é genial, nem toda lucidez é velha. (Chico Buarque). ${ }^{1}$

Este artigo é resultado de ações articuladas ao projeto de pesquisa "A Institucionalidade da Educação Profissional no Pará", financiado pelo CNPq, que tinha como foco central as práticas de educação profissional desenvolvidas no Estado do Pará.

\footnotetext{
Doutor em Educação, Universidade Federal de Minas Gerais; Pesquisador do CNPq; Professor Associado da Universidade Federal do Pará. E-mail: rlima@ufpa.br

1 Resposta dada a um repórter que perguntou ao compositor brasileiro Chico Buarque, em 1968: "Mas como, Chico, mais um samba? Você não acha que isso já está superado?"
} 
Naquela pesquisa. buscamos identificar mudanças quantitativas e qualitativas no quadro institucional da educação profissional, em particular, buscamos identificar os impactos de um conjunto de políticas de educação profissional que tinham como ponto comum a idéia de construção de uma nova institucionalidade da educação profissional em nosso país ${ }^{2}$. Estas políticas, emanadas de diferentes ministérios do governo brasileiro, foram implementadas na década de 1990, durante o Governo de Fernando Henrique Cardoso.

O estudo do projeto da "nova institucionalidade" da educação profissional brasileira foi desenvolvido a partir da observação, na realidade paraense, dos impactos dos diferentes programas que assumiam o projeto como meta. Assim, procuramos observar duas dimensões da realidade: primeiro buscamos identificar possíveis alterações no quadro das instituições que têm ofertado ações de educação profissional e depois buscamos identificar a introdução de inovações metodológicas que revelassem o conteúdo pedagógico da institucionalidade proposta. Partimos do suposto de que há uma grande distância entre o discurso do novo, o projeto do novo e a construção do novo - por isso nos concentramos em resultados concretos gerados pelas ações governamentais direcionadas para a construção de uma forma da fazer a formação de trabalhadores no Brasil.

\section{0 projeto da "nova institucionalidade" da educação profissional}

Novos processos de trabalho têm emergido, substituindo a produção em série e de massas pela especialização flexível por novos padrões de busca de produtividade, por novas formas de adequação da produção à lógica do mercado.

Essa situação incide diretamente sobre os sistemas e programas de educação profissional. Se sob a ótica taylorista-fordista a educação profissional assume um caráter restrito de adestramento de mão de obra, sendo a formação baseada na transmissão de conhecimentos ordenados e sistematizados, de habilidades e destrezas, sob o novo paradigma, observa-se a preocupação, cada vez maior, com a formação para uma nova cultura de trabalho e produção; cultura essa, por sua vez, incorporada como estratégia operacional na busca da qualidade e da produtividade. Nesse sentido, a formação profissional pode estar conjugada à polivalência, ao enriquecimento das tarefas e ao aumento das responsabilidades do indivíduo sobre o seu desempenho, valorizando tanto as aprendizagens obtidas por meio de processos educativos formais

2 Planfor - Plano Nacional de Qualificação Profissional, o Proep - Programa de Expansão da Educação Profissional, do Ministério da Educação, o PCS - Programa de Capacitação Solidária e Profae - Projeto de Profissionalização dos Trabalhadores da Área de Enfermagem. 
como informais que se dão dentro e fora dos ambientes de trabalho. Trata-se, portanto, da tentativa de produção de um tipo humano adequado aos tempos atuais.

Para responder à nova realidade da sociedade capitalista, o Governo de Fernando Henrique Cardoso formulou políticas educacionais com o intuito de ir ao encontro dos interesses do setor produtivo, adequando o aparelho educacional brasileiro às exigências do mercado. Como resultado das políticas oficiais dos anos 1990, o quadro institucional brasileiro ganhou uma nova configuração.

O projeto da "nova institucionalidade" da educação profissional brasileira pode ser compreendido como uma estratégia político-pedagógica de ajustar a formação da mão-de-obra à nova realidade técnica em que se realiza a acumulação capitalista, marcada pela emergência do modelo de acumulação flexível.

A consolidação dessa nova institucionalidade de educação profissional no Brasil foi apresentada como um dos objetivos principais do Planfor ${ }^{3}$, (BRASIL, 1996), a principal política de formação profissional do Governo Fernando Henrique Cardoso, mantida pelo atual governo sob a denominação de PNQ - Plano Nacional de Qualificação. De modo mais ou menos explícito, esse projeto também estava presente em outros programas governamentais de educação profissional tais como o PCS - Programa de Capacitação Solidária, do Ministério da Assistência, o Proep - Programa de Expansão da Educação Profissional, vinculado ao Ministério da Educação, e o Profae - Projeto de Profissionalização dos Trabalhadores da Área de Enfermagem, do Ministério da Saúde, todos originários da década de $1990 .{ }^{4}$

\section{a) A velha institucionalidade, o Sistema $\mathrm{S}$ e as séries metódicas}

A "nova" institucionalidade seria substituta da "velha", representada pelo modelo de formação de trabalhadores inaugurado nos anos 1930-1940, nascido junto com a industrialização brasileira, marcadamente pelo nascimento do SENAI em 1942 e das leis orgânicas do ensino ${ }^{5}$, que foram respostas do Estado e dos empresários, à então nova demanda por formação do trabalhador. Para o Planfor

3 Hoje PNQ - Plano Nacional de Qualificação.

4 Alguns destes programas ainda estão em execução, com denominações diferentes ou com conteúdo parcialmente alterado.

5 "Durante o Estado Novo (1937-1945) a regulamentação do ensino foi levada a efeito a partir de 1942, com a Reforma Capanema, sob o nome de Leis Orgânicas do Ensino, que estruturou o ensino industrial, reformou o ensino comercial e criou o Serviço Nacional de Aprendizagem Industrial - SENAI, como também trouxe mudanças no ensino secundário" (Andreotti, 2008). Mais tarde foi normatizado o ensino primário, o normal e o agrícola. 
o Sistema "S" (SENAI, SENAC, SENAR, SENAT, SEBRAE e SESCOOP) e as escolas técnicas / CEFETs, seriam a representação do "velho" modo de fazer a formação profissional no Brasil. ${ }^{6}$

De acordo com Oliveira (1998), nesses anos nascem o pensamento e a ideologia do empresariado industrial no Brasil, de forma a requerer um ensino profissional que a eles atendesse e um sistema de ensino que o promovesse, sob seus cuidados. Esta pesquisadora trabalha a tese de que os processos de industrialização fizeram surgir uma nova classe social: a dos empresários, num contexto político que o requeria, para se fortalecer, como também requeria o industrialismo, para tais fins. Assim, o momento em que nasce o empresariado industrial brasileiro nasce também uma ideologia para sustentá-lo.

Como marca da educação profissional nascente junto com Sistema S, Cunha (2000) explicita que ocorreu a incorporação das séries metódicas de ofício por essas instituições, especificamente pelo SENAI e pela rede federal de educação profissional, deu-se porque respondia aos anseios e às necessidades do setor produtivo emergente daquele momento, pois possibilitava o disciplinamento das condições de trabalho encontradas na empresa.

De acordo com esse autor, essa metodologia de ensino, identificada como pedagogia da educação profissional por excelência, compreendia quatro fases distintas que eram aplicáveis em qualquer situação de aprendizagem, privilegiava a individualidade do aluno, o estudo do assunto, a comprovação do conhecimento e a aplicação, generalização ou transferência do conhecimento. No processo de ensino e aprendizagem, privilegiavase o método de instrução individual, tal qual Cunha (2000, p. 23) descreve:

Cada aluno deve ter a possibilidade de iniciar aprendizagem e terminá-la quando estiver preparado para isso, sem levar em conta o nível de adiantamento de seus colegas; o docente deve poder atender cada aluno individualmente e cuidar, ao mesmo tempo, do grupo todo, oferecendo-lhes estimulação e despertando o interesse; cada aluno deveria receber assistência que necessitar, sem interferir com o progresso dos demais colegas; cada aluno deve progredir de acordo com suas aptidões, seus esforços e interesses, sem prejudicar ou ser prejudicado pelo progresso de seus companheiros de grupo.

6 No governo de Fernando Henrique vale ressaltar as discussões do "Planejamento Político Estratégico de 1995-1998" firmado em documento do Ministério da Educação em 1995. Nele se anunciava a intenção de reformar a educação profissional, pois se entendia que as instituições federais de ensino técnico, escolas técnicas e centros de educação tecnológica, apresentavam "problemas e distorções". 
A metodologia de ensino correspondia a um enquadramento intelectual que condicionava o aprendiz a limitar-se à reprodução dos conhecimentos já elaborados, além do que conduzia a uma acomodação ao status de operário e de conformismo a ordem social. Cabia à instituição de ensino profissional o papel de reproduzir política e ideologicamente as condições de trabalho da fábrica, indispensáveis à produção, onde alguém tinha o direito de mandar e o poder de fazer obedecer.

Assim, a institucionalização da educação profissional foi pautada numa pedagogia tecnicista e organizada sob forte hierarquização das funções técnicas (e docentes) de acordo com os ditames do modo de produção taylorista-fordista. Na organização do trabalho escolar fazia-se o uso de forte hierarquização das funções docentes e técnicas e de métodos de ensino programados, os quais priorizavam o treinamento e o disciplinamento do aluno por meio do controle das situações de aprendizagem. Os conteúdos eram organizados de forma sequencial e hierárquica, por meio de disciplinas ou temas fragmentados. O conhecimento era compreendido numa lógica cartesiana e transmitido de maneira que o aluno o assimilasse e o reproduzisse.

Para o MTE/SPPE ${ }^{7}$ (apud CAMARGO, 2002), são vários os termos que configurariam uma nova e uma "velha institucionalidade" da educação profissional. Expressões como: qualificação voltada para a habilidade, saber fazer, disciplina, obediência, conformidade a normas, reação, memorização, execução, concentração, formação curta ou longa e individual; educação profissional dicotômica à educação geral, em redes e sistemas nacionais, com clientelas restritas, centralizadas, voltadas para homens brancos, centralizada, sob a gestão do governo e empresários, de longa duração, escolar, com foco na oferta de formação, assistencialista e sob a ótica do "operário padrão" configurariam um quadro conceitual que permite identificar a "velha institucionalidade". Esta seria adequada ao padrão taylorista-fordista de acumulação produtiva.

\section{b) A "nova" institucionalidade da educação profissional e a emergência da lógica das competências}

A "nova institucionalidade" seria revelada por outro quadro conceitual: qualificação voltada para a competência, aprender a ser e aprender, autocontrole, iniciativa, gestão do aleatório, ação e pró-ação, raciocínio, diagnóstico, atenção, formação contínua, coletiva e capacidade de comunicação; educação profissional

7 Secretaria de Políticas Públicas de Emprego do MTE. 
complementar à escolarização, com multiplicidade de atores e agentes, voltada para a $\mathrm{PEA}^{8}$, com foco na diversidade, descentralizada, gestão tri/multipartite, formação permanente, contextualizada, com foco na demanda do setor produtivo, voltada para a geração de renda e com base na idéia do "cidadão produtivo" (CAMARGO, 2002). Tal institucionalidade seria mais adequada ao modelo de acumulação flexível.

Deve-se considerar que tais quadros não revelam per se os significados e o conteúdo das ações de formação de trabalhadores, no entanto, pode-se concordar que os mesmos são indícios bastante significativos de tendências formativas em educação profissional.

As noções têm a ver com o uso que os conceitos assumem no interior dos processos produtivos e formativos. Nesta perspectiva, as características como iniciativa e capacidade de comunicação, por exemplo, não podem ser precipitadamente entendidas como indicadores da autonomização dos sujeitos. Elas requerem contextualização e aprofundamento para serem compreendidas em função de seu uso histórico (ARAUJO, 1996).

Tomar um ou outro quadro conceitual como referência não implica a inexistência de outros quadros possíveis relacionados a processos de emancipação da classe trabalhadora. Em especial, um quadro conceitual associado a projetos educativos que, mesmo não se tendo constituindo em referência para significativas experiências educacionais brasileiras, tem sido preconizado por um crescente número de educadores e pesquisadores, que buscam associar os processos de formação, particularmente da classe trabalhadora, com o ideário da emancipação desta classe.

A "nova institucionalidade" deveria ainda ser compreendida a partir da implementação de algumas estratégias comuns: a) a busca pela maior vinculação dos processos formativos à nova realidade da empresa integrada e flexível, b ) a expansão da formação profissional apartada dos processos de escolarização, c) a ampliação das agências de formação com o incentivo a organizações privadas e não governamentais, d) novas estratégias de organização e financiamento da educação profissional, e) a focalização da clientela e f) a referência na lógica das competências.

8 População Economicamente Ativa. 
As políticas oficiais desse período tinham como referência a lógica das competências, marcando assim a emergência de uma noção que passa a ser estruturante na definição das políticas e práticas de educação profissional oriundas dos organismos oficiais brasileiros. Uma possível Pedagogia das Competências foi apresentada como uma novidade capaz de produzir o desenvolvimento das capacidades humanas que a nova realidade requeria.

A partir da noção de competência, um novo discurso sobre formação profissional se apresentou, prometendo ser capaz de responder às demandas da sociedade, dos indivíduos e do mercado de trabalho, no qual se demandam novas práticas formativas.

A formação dos trabalhadores passa, então, a ter como objetivo o desenvolvimento de competências. Nessa perspectiva, a formação assume como finalidade capacitar indivíduos para que tenham condições de disponibilizar durante seu desempenho profissional os atributos adquiridos na vida social, escolar, pessoal e laboral, preparando-os para lidar com a incerteza, com a flexibilidade e a rapidez na resolução de problemas (KUENZER, 2000).

É essa noção de competências que vem orientando as mudanças ocorridas no mundo do trabalho e a elaboração de políticas para a educação. No Brasil, a educação profissional estatal, desde o início da década de 1990, vem sendo reorganizada sob essa nova perspectiva.

A formação por competências representa a principal referência das novas estratégias de educação profissional, apresentando-se como algo novo, colocando em xeque o atual sistema de ensino e passando a exigir uma nova organização pedagógica que leve em conta a diversidade dos processos educativos.

De acordo com Santos (2004), a formação por competências representa um novo paradigma educacional, que utiliza outras metodologias de ensino, com objetivo de desenvolver no aluno a capacidade de "aprender a aprender".

Nessa nova lógica formativa, os conteúdos explícitos ganham um sentido largo, constituindo-se não somente dos conhecimentos teóricos formalizados nas matérias disciplinares, mas de atitudes, comportamentos, hábitos e posturas que possam compor uma capacidade de trabalho mutante. A ampliação do que se entende por conteúdos é acompanhada pela desvalorização da ciência. A 
organização dos conteúdos passa a obedecer a critérios objetivos referenciados nas competências necessárias às atividades profissionais (ARAUJO, 2001).

O modelo de organização desses conteúdos passa a ser prioritariamente em módulos, direcionados para o desenvolvimento da capacidade de resolução de problemas, valorizando o conhecimento da realidade (experiências e saberes profissionais) e assumindo a idéia de aprendizagem significativa, ou seja, aplicável em diversos contextos e que possa ser atualizada, quando for preciso, para que se continue a aprender, possibilitando assim uma maior flexibilidade na formação do trabalhador.

Com relação à avaliação por competência, privilegiam aspectos como a subjetividade, as diferenças, a capacidade que o aluno tem frente a uma situação inesperada de resoluções de problemas. Leva-se em consideração a competência adquirida com o conhecimento, somada às atitudes e ao desenvolvimento de habilidades adequadas ao trabalho.

De acordo com Melchior (2003), em uma profissão que lida com o ser humano, as competências profissionais consistem, em larga medida, em dominar as distâncias, tanto interpessoais quanto interculturais, que criam obstáculos à comunicação, representando assim um saber agir apoiado na mobilização e na utilização eficaz de um conjunto de recursos.

Nesse processo de ensino-aprendizagem por competências, o aprendiz passaria a ser responsável pelo seu desempenho, e o professor deixaria de ser o transmissor da informação para ser facilitador da construção da competência.

Com a Pedagogia das Competências busca-se estreitar o vínculo entre sistema educacional e sistema ocupacional. Este vínculo, no entanto, nunca deixou de existir, não sendo, portanto, uma novidade a proposta dessa aproximação, pois a história da educação profissional sempre esteve associada, de modo subordinado, à história do desenvolvimento econômico, assim como às formas de organização e de gestão do trabalho.

É com base na idéia das competências, enquanto referência para estratégias formativas voltadas para o atendimento das exigências do mercado de trabalho, que a proposta da constituição de uma nova institucionalidade para a educação profissional tem buscado fazer-se hegemônica. 


\section{Uma nova institucionalidade? A experiência paraense}

A "nova" institucionalidade tem fundamento, basicamente, em dois princípios, que são: a propalada inadequação dos sistemas tradicionais de formação profissional e a existência de uma rede maior de entidades de educação profissional até então desconhecida e não mobilizada de forma orgânica. Essa suposta nova rede de educação profissional foi fomentada pelo Planfor, a partir de 1996, cujos princípios levam ao pressuposto de que o sistema de ensino profissional tradicional não mais atenderia às necessidades de formação profissional geradas pelas mudanças nas relações de trabalho.

O Planfor e outros programas de formação (em particular o Proep, o Profae e o PCS) se orientavam por esta lógica. Assim, enquanto políticas de financiamento da educação profissional buscavam orientar o uso dos recursos públicos nesta direção. Para implementar ações que facilitassem a construção do "novo projeto" o Estado do Pará recebeu cerca de 100 milhões de reais destes 4 programas, entre 1995 a 2004 (ARAUJO et al 2007), e diferentes ações foram desenvolvidas nesse Estado sob as referências indicadas. Mas nem sempre os resultados alcançados revelam a consecução dos objetivos anunciados.

Do ponto de vista quantitativo podemos observar uma evolução no quadro institucional da educação profissional paraense.

Se em 1995 (SUDAM, 1996), existiam 26 entidades executoras de educação profissional no Estado do Pará9, que contavam com 27 unidades de ensino, já no ano de 1999, outra pesquisa encomendada pela Secretaria de Trabalho do Estado do Pará evidencia o número de 625 unidades de ensino naquele ano (FLACSO, 2000), entre as quais 151 (cento e cinquenta e uma) estavam localizadas na cidade de Belém e 474 (quatrocentas e setenta e quatro) nos demais municípios do Estado.

Em levantamento feito por pesquisadores vinculados ao GEPTE - Grupo de Estudos e Pesquisas sobre Trabalho e Educação da UFPA foi identificada, no ano de 2003, a existência de 164 entidades de educação profissional no Município de Belém.

O quadro a seguir permite a visualização da evolução das instituições que têm ofertado educação profissional no Município de Belém.

9 Os dados desta pesquisa devem ser relativizados em função da metodologia utilizada, que contabilizou apenas as entidades respondentes de questionários encaminhados por correio. 
Quadro1 - institucional da educação profissional em Belém (1995 a 2003)

\begin{tabular}{|c|c|c|c|c|c|c|c|c|c|c|}
\hline \multirow{2}{*}{ Ano } & $\begin{array}{c}\text { Nível / } \\
\text { categoria }\end{array}$ & Fed. & Esta. & Munic. & ONGs & Sist. S & Sindic. & Priv. & S/inf. & Total \\
\hline \multirow{3}{*}{1995} & Nível Técnico & 1 & 13 & - & - & - & - & - & - & 14 \\
\cline { 2 - 13 } & EP Livre & - & 1 & 1 & 4 & 4 & - & - & 2 & 12 \\
\cline { 2 - 13 } & Total & 1 & 14 & 1 & 4 & 4 & - & - & 2 & 26 \\
\hline \multirow{3}{*}{1999} & Nível Técnico & 2 & 13 & 1 & - & - & - & 8 & - & 24 \\
\cline { 2 - 12 } & EP Livre & - & - & - & 34 & 6 & 12 & 55 & 4 & 111 \\
\cline { 2 - 12 } & Total & 2 & 13 & 1 & 34 & 6 & 12 & 63 & 4 & 135 \\
\hline \multirow{3}{*}{2003} & Nível Técnico & 3 & 2 & 1 & - & - & - & 20 & - & 26 \\
\cline { 2 - 12 } & EP Livre & 4 & 4 & 5 & 42 & 6 & 12 & 55 & 10 & 138 \\
\cline { 2 - 12 } & TOTAL & 7 & 6 & 6 & 42 & 6 & 12 & 75 & 10 & 164 \\
\hline
\end{tabular}

Fontes: Sudam (1996); Flacso (2000); Brasil (2004); Pereira (2003) adaptado pelo autor. (2014)

Podemos afirmar que, a partir da implementação de programas como o Planfor, o Proep, o Profae e o PCS, fortemente impactados pelo reconhecimento dos processos de reestruturação produtiva, pelas políticas educacionais de caráter neoliberal e pela emergência de novas demandas de formação identificadas com o modelo de competências - é perceptível a constituição de modificações no quadro institucional da educação profissional em Belém, com o surgimento de novos atores, mais do que quintuplicando o número de entidades existentes em 1995.

$\mathrm{Na}$ oferta da educação profissional livre houve um crescimento grande entre todas as categorias de entidades, mas, de maneira mais acentuada, entre aquelas identificadas com o movimento sindical, aquelas do setor privado e as ofertadas por Organizações não governamentais. Entre as entidades que ofertam educação profissional de nível médio, verificamos um pequeno crescimento das entidades públicas federal e municipal e a queda vertiginosa da esfera pública estadual na oferta de educação profissional, ao lado do grave crescimento do setor privado na oferta dessa modalidade de educação profissional.

Sem que se levem em conta as matrículas, de modo geral, perde importância o Sistema "S" e as entidades estaduais, em benefício das organizações privadas, tal como preconizava Leite (1999). 
Com relação ao Sistema "S", verificamos apenas o crescimento dessas instituições, entre o ano de 1995 a 2004, de 4 (quatro) - SENAI, SENAC, SENAR e SEBRAE - quando passaram para 6 (seis) e foram incluídos SESCOOP e SENAT, contendo com 9 unidades de ensino (GALVÃO, 2006). Com tudo isso, pode-se afirmar que houve consideráveis modificações no quadro institucional da educação profissional de nível médio em Belém.

Do ponto de vista das estratégias de organização e de construção das práticas formativas, destacamos que ainda convivem, nas instituições, práticas tradicionais junto com novas outras pautadas na idéia de competências.

Do ponto de vista do financiamento das ações de formação, ainda é o Estado a principal fonte de recursos, apesar de este ter-se retirado da execução das ações de formação, particularmente em nível estadual.

A gestão apresenta-se ainda centralizada e fortemente hierarquizada, não se visualizando estratégias efetivas de transparência e de gestão colegiada da educação profissional paraense.

A grande referência para as práticas formativas são as demandas identificadas com o mercado de trabalho (apesar de nenhuma entidade ter definido claramente estratégias de análise ocupacional). A preocupação com o homem é secundária e impregnada por uma visão assistencialista e cristã.

Paradoxalmente, as novas formas de fazer a educação profissional, pautadas na lógica das competências, parecem estar mais presentes em instituições tradicionais como o CEFET-PA e o SENAI (que seriam a expressão do "velho").

O ideário da Pedagogia das Competências está presente nas instituições, mas, não, nas suas práticas. A noção de competência ainda é pouco compreendida e coloca problemas reais nos momentos em que os professores se propõem a organizar os currículos, definir estratégias de ensino e proceder a avaliações.

O resultado pedagógico mais efetivo do projeto da nova institucionalidade da educação profissional é o fortalecimento do ideário pragmatista, que se renova enquanto ideologia orientadora das práticas de organização e de gestão da formação de trabalhadores. 
Enfim, observamos nas instituições que trabalham com educação profissional que, apesar de assumirem o discurso da lógica das competências, esta ainda é pouco compreendida pelos seus agentes. Por essa razão, a organização das aulas e principalmente as questões referentes à avaliação parecem não estar compatíveis com os documentos das instituições, mas, sim, ainda com certo atrelamento a mecanismos característicos do modelo tradicional de educação profissional, como a ênfase na memorização e no trabalho especializado.

Mesmo que fosse "bem compreendida" a lógica das competências representa, no máximo, a renovação do "velho", compreendendo uma orientação pedagógica preocupada em promover o ajustamento do homem à realidade dada e à sua conformação com a ordem burguesa, valorizando os saberes instrumentais e úteis aos processos de acumulação capitalista.

\section{Considerações finais}

Sob a retórica da renovação da educação profissional, recupera-se a idéia de saber útil como referência para práticas formativas, mobilizável em função das necessidades surgidas no interior dos processos produtivos, estabelecendose, assim, uma relação direta entre necessidades produtivas e conteúdos de formação. Tal estratégia vincula situação de trabalho e formação, mobilizando conhecimentos e capacidades em função dos objetivos empresariais e das necessidades de resolução de problemas produtivos, tornando prescindível a compreensão da lógica própria dos objetos do conhecimento.

Desarticula-se, assim, prática e teoria e pressupõe-se uma relação entre esses dois termos, de modo que o segundo termo esteja a reboque do primeiro. Os conteúdos, assim, são tratados apenas enquanto informações que devem ser mobilizadas de acordo com as necessidades emanadas das práticas concretas desprezando a necessidade de tratamento científico aos mesmos.

As referências para estas estratégias não têm nada de novo, estão presentes nas formulações das correntes pragmáticas do início do século passado que defendiam o saber útil e o ajustamento da formação à realidade dada.

Ao considerar a formação profissional apenas a partir daquilo que é útil ao sistema produtivo, e não daquilo que é necessário à sociedade e à elevação da compreensão 
do trabalhador sobre seu trabalho, o projeto da nova institucionalidade da educação profissional descomprometeu-se com a construção do futuro (do efetivamente novo) e se conformou com o existente, reforçando as relações sociais de dominação e de exploração do trabalho do técnico e dos demais trabalhadores. Esse projeto apresentou uma teleologia subordinada às demandas específicas das empresas, divulgando um discurso segundo o qual a atual configuração societal oferece condições para a produção da felicidade.

Se, por um lado, é possível verificarmos que a renovação produzida foi meramente formal, e que os objetivos anunciados foram muito parcamente cumpridos, por outro lado, é necessário reconhecer que outros resultados foram alcançados.

Para nós o principal produto desse projeto foi a renovação do discurso segundo o qual cabe à educação submeter-se aos interesses estreitos e imediatos do mercado de trabalho. Renovou-se, assim, uma ideologia de legitimação da sociabilidade do capital e, para tanto, serviu bastante a lógica das competências.

Machado (2002), ao abordar a institucionalização das competências no Brasil, enfatiza que esta se deu de modo particular no Brasil, e que a compreensão à brasileira vem traduzindo as competências com forma e conteúdo ultraliberais, tanto nas políticas estatais quanto na esfera da gestão do trabalho.

Para Machado, se esta lógica se propagar em escala, alcançar-se-á o ápice da institucionalização: a legitimação social.

Esta autora conclui afirmando que o processo de institucionalização da lógica das competências, no Brasil, integra, portanto, um conjunto de estratégias que visam à recomposição dos mecanismos de instrumentalização das individualidades. E diz que o processo de institucionalização da lógica das competências representa, no caso brasileiro, buscar a refuncionalização das relações entre produção, educação e escola tendo em vista as novas demandas dos mercados ultralivres de trabalho em decorrência das flexibilizações e desregulamentações.

Sistemas de formação focados no desenvolvimento do saber-fazer estão destinados a enfrentar problemas tendo em vista que buscam o desenvolvimento de habilidades para funções imprevistas. Esta referência revela não uma ruptura com os conceitos que historicamente têm orientado a educação profissional, mas 
a continuidade de um ideário que pressupõe a educação profissional voltado para o desenvolvimento de habilidades práticas. Dessa forma idéias como treinamento apenas são travestidas na Pedagogia das Competências, mas mantêm o mesmo conteúdo de uma educação estreita e instrumental.

Por fim, se o projeto da "nova institucionalidade da educação profissional" revelou-se velho já em seu nascedouro, em função do uso de referências velhas e do comprometimento com a realidade dada, o efetivamente novo ainda está por ser reconhecido, debatido e construído nas instituições de educação profissional. Pautado em referências que busquem a ruptura com a ideologia do status quo, focando nas necessidades amplas dos homens e tendo os olhos no futuro, este projeto deve estar comprometido com o revolucionamento, social e pedagógico, do presente. Só aí poderemos começar a construir o efetivamente novo.

Na perspectiva aqui assumida, a educação do trabalhador não pode restringir-se àquilo que corresponde às necessidades imediatas do capital, ao adestramento, à simples adaptação dos indivíduos, a uma prática utilitarista. Mas, para que se constitua como uma formação ampla, precisa entre outras coisas, articular-se aos processos de escolarização e assegurar o reconhecimento do contexto históricosocial em que o trabalho se realiza. Uma educação que se volte para a ampliação dos horizontes de conhecimentos, observando uma atenção aos determinantes sociais, econômicos e políticos das situações de vida.

Sob esta perspectiva, o novo pode ser representado por uma abordagem de educação profissional que vise não apenas ao aumento da produtividade, mas à formação omnilateral dos homens, associada a processos de emancipação da classe trabalhadora.

\section{Referências}

ARAUJO, R. M. de L. Inovações Organizacionais e Qualificação: os aspectos atitudinais da qualificação. Dissertação (Mestrado)-Programa de Estudos PósGraduados em História e Filosofia da Educação, Pontifícia Universidade Católica de São Paulo, São Paulo, 1996.

ARAUJO, R. M. de L. Desenvolvimento de competências profissionais: as incoerências de um discurso. 2001.218f. Tese (Doutorado em Educação)- Faculdade de Educação da Universidade Federal de Minas Gerais. Belo Horizonte, 2001. 
ARAUJO, R. M. L. et al. A educação profissional do Pará. Belém: EDUFPA, 2007.

BRASIL. PLANFOR: termos de referência. Brasília, DF: Ministério do Trabalho e Emprego, 1996.

CAMARGO, C. R. (Org.). Experiências inovadoras de educação profissional: memória em construção de experiências inovadoras na qualificação do trabalhador (1996-1999). São Paulo: UNESP; Brasília, DF: Flacso, 2002.

CUNHA, L. O Ensino de ofícios nos primórdios da industrialização. São Paulo: UNESP, 2000.

FLACSO. FACULDADE LATINO-AMERICANA DE CIÊNCIAS SOCIAIS. Cadastro das Entidades de Educação Profissional do Estado do Pará. Brasília, DF: Flacso, 2000.

GALVÃO, R. C. A Formação Profissional do Sistema S no Contexto Paraense: Relatório técnico-científico de bolsista PIBIC-UFPA-CNPQ. Belém: [s.n.], 2006.

KUENZER, A. Educação Profissional: categorias para uma nova pedagogia do trabalho Disponível em: <www.senac.br/boletim/boltec252b.htm>. Acesso em: 25 jul. 2000.

LEITE, E. O desfile dos atores no enredo da nova institucionalidade da educação profissional no Brasil: um samba articulado?. Belo Horizonte: Texto, 1999.

MACHADO, L. R. de S. A institucionalização da lógica das competências no Brasil. Disponível em : < nocaodecopmpetencias.hpg.bol.com>. Acesso em: 08 dez. 2002.

MELCHIOR, M. A construção de Competências. In: .Da Avaliação dos saberes à Construção de Competências. Porto Alegre: Premier, 2003.

OLIVEIRA, M. T. C. Da formação profissional à educação para o trabalho e a cidadania: uma reflexão sobre as recentes transformações do pensamento do empresariado industrial brasileiro sobre a capacitação profissional. 1998. 214p. Dissertação (Mestrado em Educação), Pontifícia Universidade Católica de Rio de Janeiro, 1998. 
PEREIRA, M. de O. A formação de jovens no Município de Belém realizada por ONGs em parceira com o Programa Capacitação Solidária. 2003. Dissertação (Mestrado) -Programa de Pós-graduação em Mestrado de Serviço Social da UFPA. Belém: UFPA, 2003.

SANTOS, M. R. S. dos. Educação profissional e Tecnológica. In: . $A$ contra-reforma da Educação Superior: uma análise do ANDES-SN das principais iniciativas do governo Lula da Silva. Brasília, DF: ANDES, 2004.

SUDAM. SUPERINTENDÊNCIA DO DESENVOLVIMENTO DA AMAZÔNIA. PNUD. PROGRAMA DAS NAÇÕES UNIDAS PARA O DESENVOLVIMENTO. Formação profissional na Amazônia legal. Belém: SUDAM, 1996. $2 \mathrm{v}$.

Recebido em: 10/05/2013

Aceito para publicação em: 23/09/2013 


\section{Institutions of professional formation - history and perspectives: the project of Brazilian's professional education new intitutionalism of 1990's Abstract}

This article problematizes the project of the "new intitutionalism of professional education", present on different federal programs during the governments of President Fernando Henrique Cardoso's Government, which were meant to promote an extensive renovation of the professional education. We focused on the effects of different programs of professional education in the city of Belém, state of Pará, in the period of 1995 and 2003. We could verify that these programs had been guided by references identified with Pragmatism. And by means of observation and interviews, we could also verify that the renewal of professional education had not been accomplished and that the most evident product of the set of actions undertaken had been the reproduction of the ideas that professional education must be subordinated to the immediate interests of the market. We conclude indicating that a new professional education is still to be constructed. Keywords: Education professional. Evaluation of policies to education professional.

\section{Instituciones de formación profesional - Historia y perspectivas: el nuevo diseño institucional de la educación profesional de Brasil en la década de 1990 Resumen}

Este trabajo problematiza el proyecto del "nuevo marco institucional de la educación profesional", presente en diferentes programas federales originados durante el Gobierno de Fernando Henrique Cardoso, que quería promover una renovación conceptual amplia de la educación profesional brasileña. Nos centramos en los efectos de diversos programas de educación profesional sobre el marco institucional de la educación profesional en Belém-PA, durante el periodo de 1995 a 2003. A partir de una investigación documental se constata que los programas seguían referencias identificadas con el pragmatismo y que, a través de observaciones y entrevistas, la renovación de la educación profesional no se llevó a cabo y el producto más evidente del conjunto de medidas adoptadas fue la reproducción de la ideología según la cual la formación profesional dependia de los intereses fragmentados e inmediatos del mercado. Para finalizar, se señala que aún se debe esperar por la construcción de una nueva educación profesional. Palabras claves: Educación profesional. Evaluación de las politicas de formación profesional. 